\title{
The Role of Cognitive Factors in Year Five Pupils' Algebraic Thinking: A Structural Equation Modelling Analysis
}

\author{
Piriya Somasundram ${ }^{1 *}$ \\ ${ }^{1}$ School of Mathematical Sciences, Sunway University, MALAYSIA \\ Received 31 August 2020 - Accepted 17 November 2020
}

\begin{abstract}
Algebraic thinking in children can bridge the cognitive gap between arithmetic and algebra. This quantitative study aimed to develop and test a cognitive model that examines the cognitive factors influencing algebraic thinking among Year Five pupils. A total of 720 Year Five pupils from randomly selected national schools in Malaysia participated in this study. Two mathematics instruments were used to evaluate the participants' number, symbol, operation, and pattern senses and their algebraic thinking respectively. Data was analysed using a structural equation modelling and Partial Least Squares regression. The results indicated that the proposed cognitive factors influence algebraic thinking significantly, with the most influential factor being symbol sense followed by pattern sense, number sense, and operation sense. The finding implies that educators should consider implementing activities related to these cognitive factors when teaching mathematics to enhance the pupils' transition from arithmetic to algebra.
\end{abstract}

Keywords: Algebraic thinking, Arithmetic generalisation, functional thinking, pattern generalisation

\section{INTRODUCTION}

Algebraic thinking is the most prevalent form of formal algebra learning, and algebra accounts for most fields in mathematics (Blanton \& Kaput, 2003; Jacobs et al., 2007; Rittle-Johnson et al., 2011). Research has shown that students who completed algebra have higher chances of attending college (Kim et al., 2015). However, many students are not able to grasp and succeed in algebra learning (Swangrojn, 2003; Van Amerom, 2002), and middle-school students find learning algebra difficult due to the abstract introduction of the topic (Kaput, 2008). The reason for this abstract introduction is because arithmetic and algebra are treated as two distinct topics in school (Herscovics \& Linchevski, 1994) and many school curricula have taught them as separate topics (Van Amerom, 2002). The former involves the use of numbers directly while the latter involves the use of letters to represent numbers. As such, a cognitive gap emerges in the transition from arithmetic to algebra (Ayhan \& Nilufer, 2017). This problem can be overcome by cultivating algebraic thinking while teaching arithmetic in elementary school (Jacobs et al., 2007). As algebra is not a separate entity from arithmetic, children can be taught to think algebraically while learning arithmetic (Blanton \& Kaput, 2004; Houssart \& Evens, 2003; Warren et al., 2006). Algebra is not a topic only taught in high school.

Algebra is often associated with symbols and variables, but algebraic thinking is not necessarily so. According to Kieran's (1996, p. 275) definition,
Algebraic thinking can be interpreted as an approach to quantitative situations that emphasizes the general relational aspects with tools that are not necessarily letter-symbolic, but which can ultimately be used as cognitive support for introducing and for sustaining the more traditional discourse of school algebra.

This definition guided the current study to investigate algebraic thinking without abstract variables but rather connection or relationships between unknowns. Traditionally, algebra is often not taught in connection to the real world (Van Amerom, 2002), leading many students to view algebra as an abstract concept and subsequently failing to make sense of it. To fill this cognitive gap, cultivating algebraic thinking in

(c) 2021 by the authors; licensee Modestum. This article is an open access article distributed under the terms and conditions of the Creative Commons Attribution License (http://creativecommons.org/licenses/by/4.0/). 


\section{Contribution to the literature}

- To examine how algebraic thinking could be developed among elementary school children to bridge the cognitive gap between arithmetic and algebra.

- To assess the influence of number, symbol, operation, and pattern senses on the development of algebraic thinking among children.

- This is the first known study to examine these cognitive factors quantitatively using structural equation modelling technique.

arithmetic involves transforming and extending commonly taught mathematics in elementary school towards that of algebraic thinking with its underlying feature of generalisation (Blanton \& Kaput, 2008).

In recent studies, early algebraic thinking encompasses "mathematical relations, patterns, and arithmetical structures" (Kieran et al., 2016, p. 1). Many studies have looked into children's capability to think algebraically (Blanton \& Kaput, 2003; Brizuela \& Schliemann, 2004; Carraher \& Schliemann, 2007; Warren et al., 2006), focusing on various perspectives such as arithmetic generalisation, modelling, and functions. Based on these findings, the current study identified number sense, symbol sense, operation sense, and pattern sense as potentially influential cognitive factors. To date, the effects of these cognitive factors on Year Five pupils' algebraic thinking have not been examined. As such, the current study examined the interrelationships between these cognitive factors and algebraic thinking.

The present study proposed to extend the literature of algebraic thinking by examining the impact of cognitive factors on Year Five pupils' algebraic thinking in Malaysia. This study looked at the relationship among number sense, symbol sense, operation sense, and pattern sense and how it influences algebraic thinking among Year Five pupils. This study also analysed the direct effects and indirect effects (mediating factors) of the relationship between the four cognitive factors and algebraic thinking. The effects of cognitive factors from a quantitative perspective have not received much attention in existing literature, which is why the investigation of the four cognitive factors is crucial. The research questions that guided the study are as follows:

1. Do the proposed cognitive factors directly affect Year Five pupils' algebraic thinking?

2. To what extent does the proposed cognitive factors influence Year Five pupils' algebraic thinking?

Based on the research questions, the following hypotheses were developed:

$\mathrm{H}_{1}$ : There is a positive relationship between number sense and algebraic thinking.

$\mathrm{H}_{2}$ : There is a positive relationship between symbol sense and algebraic thinking.

$\mathrm{H}_{3}$ : There is a positive relationship between operation sense and algebraic thinking.
$\mathrm{H}_{4}$ : There is a positive relationship between pattern sense and algebraic thinking.

\section{LITERATURE REVIEW}

\section{Adaptive Control of Thought-Rational (ACT-R)}

From an information processing perspective, the cognitive development in humans involves the sequence of events that occur in a person's mind when receiving a new piece of information (Miller, 1956). Anderson (1983) developed Adaptive Control of Thought-Rational, commonly known as ACT-R theory, based on information processing theory. Three important stages are involved in the learning process: declarative stage, knowledge compilation stage, and procedural stage. In the context of mathematics, the declarative stage refers to the types of action carried out by a student based on facts, such as performing addition and subtraction. These facts related to basic arithmetic operations are stored in the declarative memory. The associative stage is when the student retrieves the facts related to arithmetic from his or her long-term memory. The procedural stage, or proceduralisation, occurs when the student applies the fact into an algebraic situation to solve a problem.

The ACT-R theory describes facts as declarative knowledge and rules as procedural knowledge (Anderson, 1983). The current study focused on the pupils' transition from arithmetic to algebra learning based on Anderson's (1983) theory of how declarative knowledge transitions to procedural knowledge through the three stages. The study looked at how a pupil learns, stores, and retrieve arithmetic facts while solving arithmetic problems that involve algebraic thinking.

\section{Algebraic Thinking}

Algebraic thinking involves strong symbolisation and generalisation (Kaput, 2008). The capability to think algebraically begins when a person is able to use a specific number to argue a general case (Blanton \& Kaput, 2003). Algebraic thinking also involves using representation and creating relationships in sensible ways and as such, focuses more on relationships between numbers and ideas of generalisation (Carraher \& Schliemann, 2007). 
Without calculating, select the best estimate for $\frac{4}{5}+\frac{6}{7}$ ? Why?

$\begin{array}{lllll}\text { (1) } 12 & \text { (2) } 10 & \text { (3) } 2 & \text { (4) } 1 & \text { (5) Without calculating can't find the answer }\end{array}$

Figure 1. An example of number sense task (Yang, 2003)

$$
\begin{aligned}
& \text { What value of } m \text { will make the following equation true? } \\
& 3 \times m+7=25
\end{aligned}
$$

Figure 2. An example of symbol sense task (Byrd et al., 2015)

Algebraic thinking does not refer to the teaching of algebra at the elementary level. It is different from formal algebra lessons in middle school and high school. Algebraic thinking bridges the cognitive gap between arithmetic learning in elementary school and algebra learning in high school. As clearly defined by Van Amerom (2002), arithmetic is working with known numbers to get a unique solution while algebra is working with unknowns to generalise a unique solution. The separation of arithmetic from algebra makes highschool students develop conceptual knowledge when learning algebra (Cai \& Moyer, 2008). Research has shown that the efficient way to learn algebra in high school is to nurture algebraic thinking skills first in elementary school (Carraher et al., 2006; Mason, 2008; Swafford \& Langrall, 2000).

\section{Cognitive Factors Associated with Algebraic Thinking}

The current study examined four cognitive factors: number sense, symbol sense, operation sense, and pattern sense. Number sense refers to the proficiency in mental calculation, computational estimation, judgment of the relative magnitude of numbers, recognition of part-whole relationships, and problem-solving (McIntosh et al., 1992). This factor encompasses the understanding of numbers and operations, with the ability to develop useful, flexible, and efficient strategies for handling numerical problems (Yang et al., 2004). Hence, a solid conceptual understanding of numbers and operations will enable a smooth transition to learning algebra (Carpenter \& Levi, 2000; Chrysostomou et al., 2013) as making sense of numbers and counting entail knowledge of spatial relationships, patterns, and combinations that coincide with early concepts of algebra. Figure 1 shows an example of a task that can be incorporated in fifth-grade mathematics to enhance number sense. This task does not focus on the addition of fractions but on how to make sense of fractions. Both fractions are close to but lesser than number 1, which means the best estimate is closer to number 2 .

Apart from number sense, making sense of symbols plays an important role in developing algebraic thinking. According to Arcavi (1994), symbol sense is "an individual's ability to understand how and when symbols can and should be used to display relationship and generalisations" (p. 31). This definition reflects algebraic thinking which involves the ability to make sense of symbols to create relationships and generalisations. Variables and the equal sign are two elements of symbols that are inevitable when learning algebra. Variables in this context do not necessarily refer to an unknown - they could be a letter that represents a number. A simple comparison problem such as $\mathrm{N}+3$ could help children develop conceptual understanding of variables (Carraher et al., 2008).

Similarly, having a conceptual understanding of the equal sign enables students to develop relational thinking and have the awareness of equality, which is the most crucial aspect of algebra learning (RittleJohnson et al., 2011). The equal sign is often viewed as operational than relational (Alibali et al., 2007), which often hinders students from developing a conceptual understanding of relationships. For example, educators should emphasise equations such as $5+2=3+4$ (Knuth et al., 2011) instead of the ordinary tasks of finding the sum for $5+2$ or $3+4$ which will not enhance students' thinking skill and symbol sense. Helping students understand the equal sign better at the elementary level would enable and prepare them in solving variables in algebra.

A study by Byrd et al. (2015) reported that the understanding of symbols contributes significantly to the learning of early algebra and mathematics. For instance, Figure 2 shows a simple task that could develop the relational understanding of an equal sign. This task progressively develops children's understanding of the equal sign, enabling them to find the corresponding value for $m$. Rote learning would lead the children to find $m$ by computational method without developing the relational thinking.

Operation sense is also crucial in developing algebraic thinking (Slavit, 1999). For instance, the following task enables students to think without abstract operational symbols: "Mike has 3 blocks, and his brother gives him 5 more blocks for Christmas, so how many does he have altogether?" (Slavit, 1999). The understanding of operations emphasises the underlying properties of operations, such as the relationship between repetitive addition and multiplication, the relationship between multiplication and division, and the ability to work with forward and backward using a mathematical sentence. These basic properties of operations will bridge the cognitive gap between arithmetic and algebra (Herscovics \& Linchevski, 1994). 


\begin{tabular}{|c|c|c|}
\hline \multicolumn{3}{|c|}{$2 \leftrightarrow 3=3 \leftrightarrow 2$} \\
\hline \multicolumn{3}{|c|}{$\begin{array}{l}\text { Note: } \& \text { could be }+ \text { (addition), }-(\text { subtraction }), \div(\text { division }) \text { or } x \\
\text { (multiplication) }\end{array}$} \\
\hline \multicolumn{3}{|c|}{ For which operations $(+,-, \div, x)$ is the above true? } \\
\hline & $2+3=3+2$ & True / False \\
\hline & $2-3=3-2$ & True / False \\
\hline & $2 \div 3=3 \div 2$ & True / False \\
\hline & $2 \times 3=3 \times 2$ & True / False \\
\hline b. & \multicolumn{2}{|c|}{ For the operations that are TRUE } \\
\hline (i) & \multicolumn{2}{|c|}{ Create two more examples } \\
\hline (ii) & \multicolumn{2}{|c|}{$\begin{array}{l}\text { Explain in writing what patterns you have } \\
\text { discovered. }\end{array}$} \\
\hline (iii) & \multicolumn{2}{|c|}{$\begin{array}{l}\text { Show me the pattern using the symbols and } \backslash \text { for the } \\
\text { numbers. }\end{array}$} \\
\hline
\end{tabular}

Figure 3. An example of operation sense task (Warren, 2003)

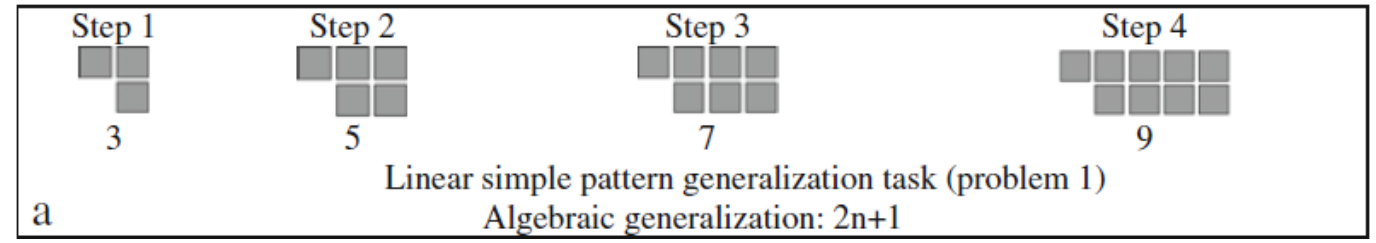

Figure 4. Linear generalization patterning task (Jurdak \& El Mouhayar, 2014)

In addition, making sense of numbers and operation helps the development of algebraic thinking by (i) doing and undoing, (ii) building rules to represent functions, and (iii) abstracting from computation (Driscoll \& Moyer, 2001).

Warren's (2003) study supports the importance of developing operation sense among elementary school children. Figure 3 shows one of the tasks used in the study, which aimed to investigate children's understanding of operations and its relationship to their development of commutative and associative laws - the two important laws when working with abstract algebra. The study found that understanding the relationship between operations assisted children in their successful transition from arithmetic to algebra.

Finally, having pattern sense leads to functional thinking that enables students to work with functions in algebra. Most of the literature on algebraic thinking discusses the ability to work with patterning activities and its contribution towards the development of algebraic thinking (Jurdak \& El Mouhayar, 2014; Lannin et al., 2006; Stacey, 1989). Patterning tasks are simple activities whereby given a series of patterns, a child should be able to predict the pattern for the subsequent or arbitrary term. Working with numerical or figural patterning tasks would help children develop a conceptual understanding of relationships between one term and another term. It also enables children to think of a "rule" to find any arbitrary terms. Making sense of this "rule" builds a foundation to understand the concept of functions in the future (Ralston, 2013).
Figure 4 shows a sample linear pattern generalisation task meant for a fifth-grade pupil to solve. This patterning task illustrates $2 n+1$. If students are exposed to this type of patterning tasks at a young age, they could develop functional thinking skills that can be applied while working with functions at middle-school level.

It is also crucial to note the role of teachers in developing these four cognitive factors - number sense, symbol sense, operation sense, and pattern sense-in their daily teaching and learning process. Most teachers often ask closed questions that focus on abstract algebraic procedures, which are not helpful in enhancing students' algebraic thinking (Schubert et al., 2013). According to Yang and Jan (2019), teachers with a background in mathematics education demonstrated number sense when they were interviewed and asked to solve number sense questions.

\section{The Conceptual Framework}

The conceptual framework for the current study is based on past studies (Arcavi, 1994; Haldar, 2014; Hsu et al., 2001; Stacey, 1989) supported by the theoretical framework that classifies the cognitive factors associated with Year Five pupils' algebraic thinking. Number sense, symbol sense, operation sense, and pattern sense are presumed to be directly associated with Year Five pupils' algebraic thinking. Figure 5 displays the conceptual framework that serves as the proposed structural model for the current research. 


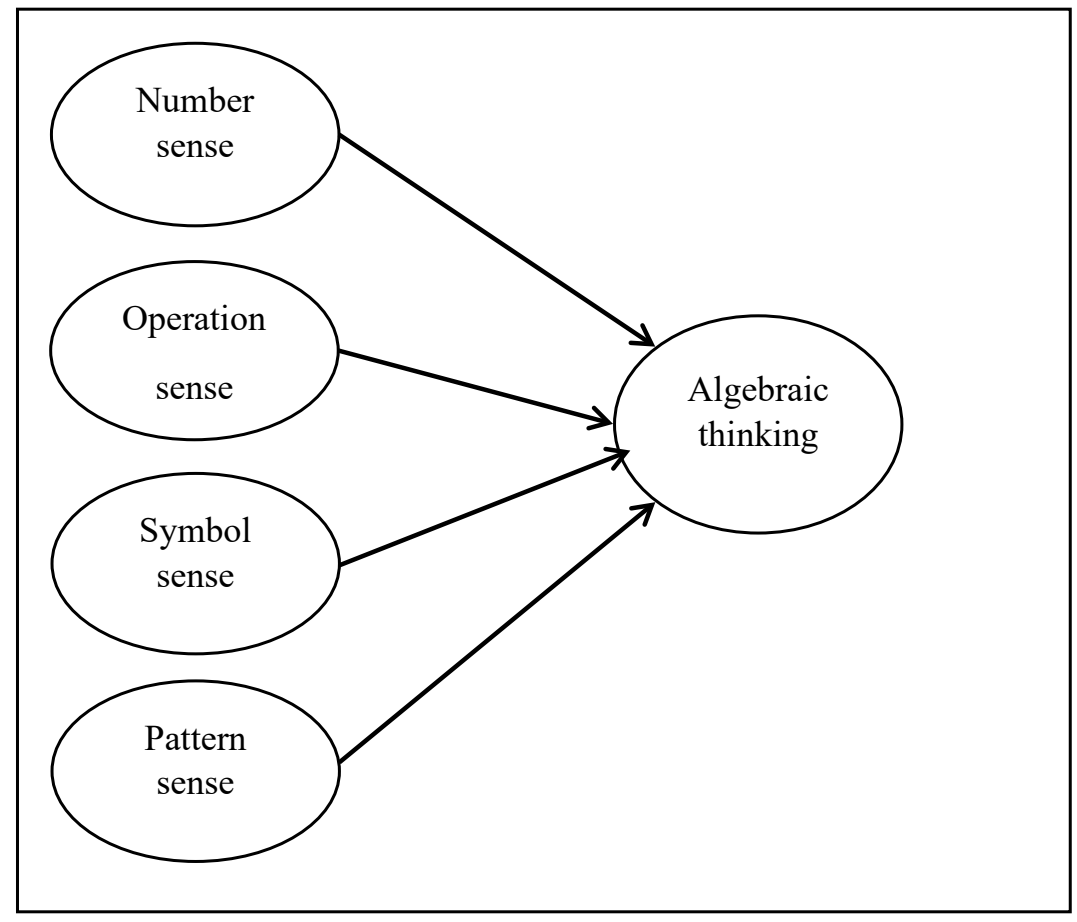

Figure 5. The conceptual framework
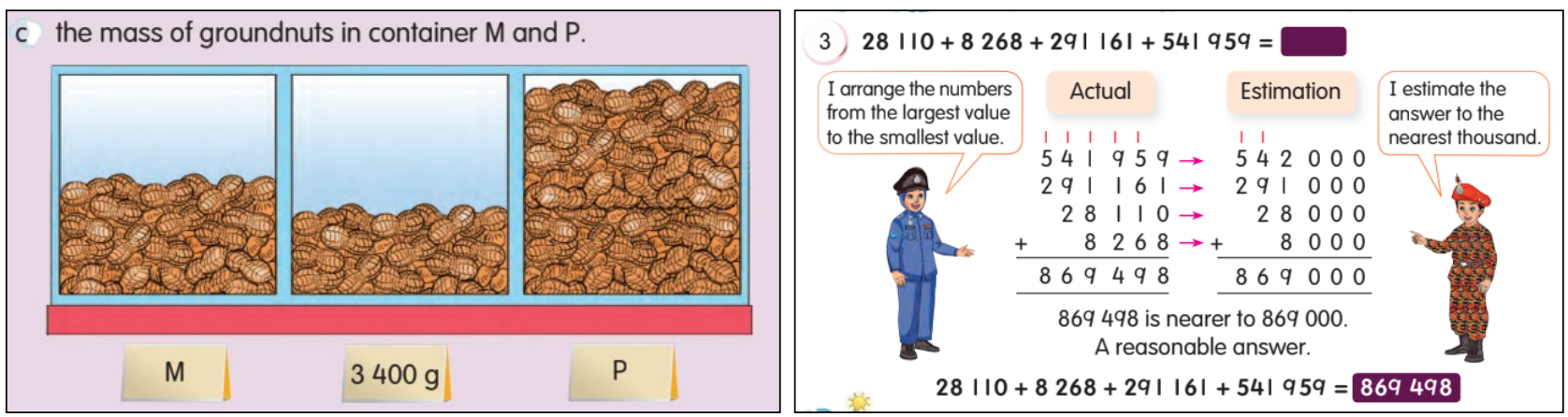

Figure 6. An example of number sense task in national curriculum textbook

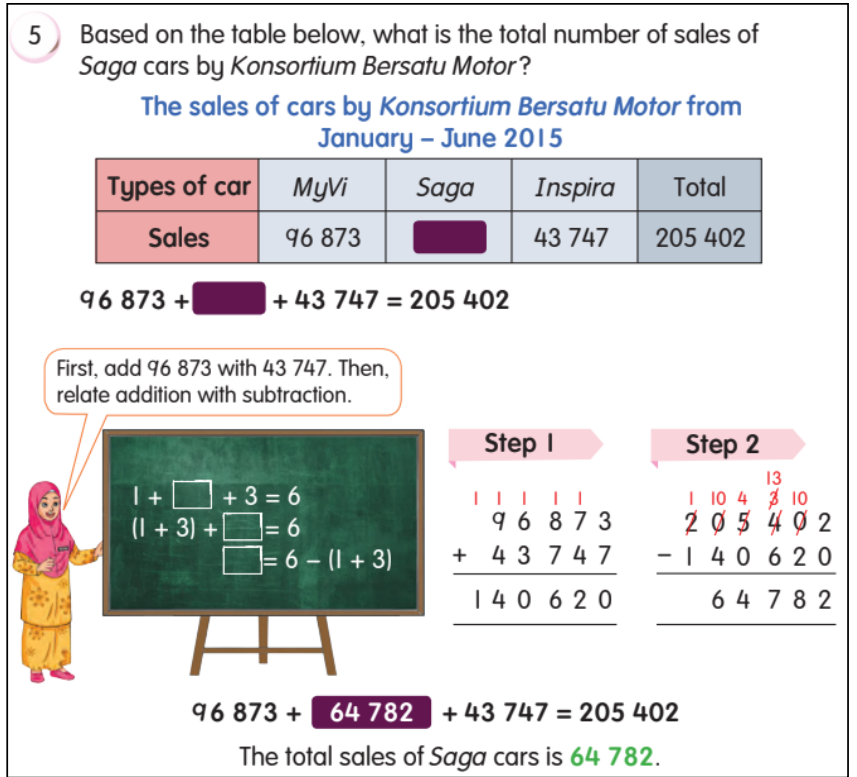

Figure 7. An example of operational sense task in national curriculum textbook
At present, the national curriculum textbooks in Malaysia comprised some elements of these cognitive factors (Chan et al., 2018). Figure 6 shows one task that requires students to make a reasonable guess of mass for containers $\mathrm{M}$ and $\mathrm{P}$ and another number sense task that requires students to perform estimation. Figure 7 shows an operation sense task but whether or not it actually involves operation sense is debatable. The task can be compared to a single-digit summation task that requires students to use the same concept in their work with larger numbers. In addition, the relationship between addition and subtraction may depend on the educator's guidance during the teaching and learning process in the classroom.

Likewise, Figure 8 shows some elements of introducing an unknown $\mathrm{K}$ but it is again comparable to a single-digit task probing students to relate the situation to calculations of larger numbers. This may lead students to practise rote learning and rely on memorisation as the task was not defined meaningfully. Figure 9 shows a task involving number pattern, whereby students are 


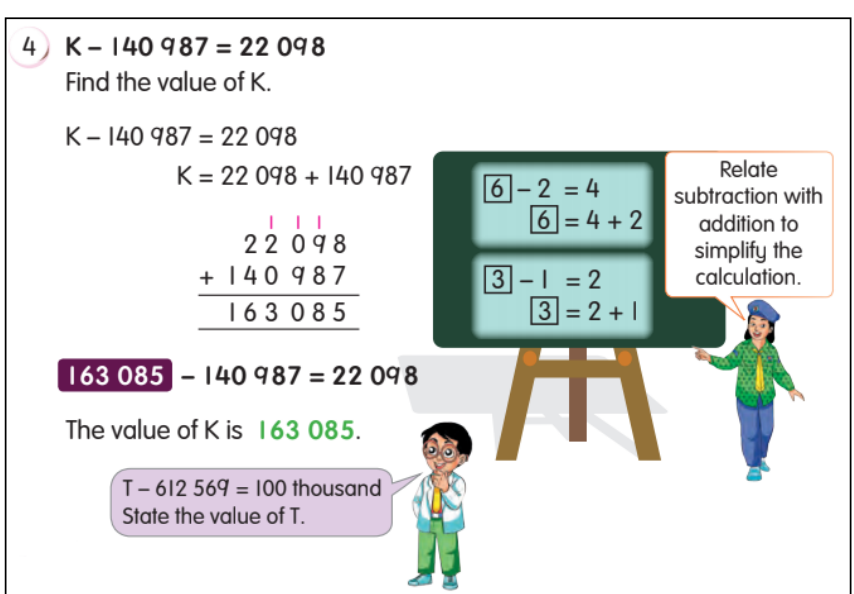

Figure 8. An example of symbol sense task in national curriculum textbook

What is the missing number in the even number pattern? Discuss.

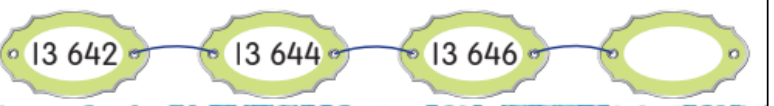

Figure 9. An example of pattern sense task in national curriculum textbook

required to guess and discuss the fourth term in the number pattern. Having students discuss the task would enable them to think how the fourth term is derived and educators should probe further by asking them to guess an arbitrary term in this pattern. By doing so, students would be able to generate a rule to find the arbitrary term in this pattern, leading to generalisation.

\section{METHODOLOGY}

\section{Participants and Procedure}

This study was designed to determine the direct, indirect, and total effects of cognitive factors that affect Year Five pupils' algebraic thinking. This study utilised a quantitative and cross-sectional approach and sample was chosen via random cluster sampling technique. All national schools in a district of Malacca, Malaysia were grouped into clusters and each school was numbered. The Rand() function in Microsoft Excel was then used to generate a random number that identified the respective schools from which Year Five pupils would be selected as participants. A total of 720 Year Five pupils from the randomly selected national schools in a district of Malacca participated in this study. The sample comprised $370(51.4 \%)$ female pupils and $350(48.6 \%)$ male pupils.

Two instruments, the Assessment of Number, Operation, Symbol, and Pattern Senses (ANOSPS) and the Algebraic Thinking Diagnostic Assessment (ATDA), were used to collect data. ANOSPS aimed to measure proposed cognitive factors namely number sense, operation sense, symbol sense, and pattern sense, while ATDA aimed to measure algebraic thinking. The participants were tested using both instruments, which were akin to mathematics tests, during their class periods in school. The tests were conducted on the same day, with a half-an-hour break in between, to ensure that the same set of pupils sat for both tests.

\section{Measures}

ANOSPS was developed to assess the proposed cognitive factors associated with the pupils' algebraic thinking. The instrument comprised 19 items adapted from literature and each item has two sections. The first section consists of multiple-choice questions that require participants to choose the correct answer from a choice of four answers. The second section requires participants to provide a reason for selecting their answer; the list of reasons is also given in a multiple-choice format and participants have to select one reason out of three. This is to ensure that participants would not select answers randomly.

ATDA was developed by Ralston (2013) and comprises 27 items that evaluate the pupils' performance in algebraic thinking in terms of arithmetic generalisation, modelling, and functions. Each item is a short-answer question and is scored on a dichotomous rating: " 1 " for correct answer and " 0 " for incorrect answer. This instrument was selected because at the time of the study, it was the only assessment tool available that encompasses all aspects of algebraic thinking in evaluating Year Five pupils' algebraic thinking.

\section{Data Analysis}

The main purpose of the present study was to investigate the relationships between cognitive factors and algebraic thinking. Partial Least Squares regression (PLS) was used for data exploration and model estimation while the evaluation and structural model estimation were performed using structural equation modelling (SEM). SEM is similar to multiple regression but it is a more powerful data analysis method that enables researchers to assess and modify theoretical models in the early stages of theory development (Anderson \& Gerbing, 1988). Besides that, it also tests all relationships involved in the model simultaneously and as a whole. SEM combines path analysis and factor analysis methods. Collected data was keyed into SPSS Version 22.0 software and analysed with SmartPLS 3.0 software.

\section{RESULTS AND DISCUSSION}

\section{Evaluation of Measurement Model}

The measurement model evaluation is performed to determine if the specified measurement model is acceptable for further data analysis. One of the major 
Table 1. Systematic evaluation of PLS-SEM results

Step 1: Evaluation of Measurement Model

Formative measurement model:

- Collinearity among indicators

- Significance and relevance of outer weights

\section{Step 2: Evaluation of Structural Model}

- Coefficients of determination $\left(R^{2}\right)$

- Predictive relevance $\left(\mathrm{Q}^{2}\right)$

- Size and significance of path coefficients

- $f^{2}$ effect sizes

$-q^{2}$ effect sizes

reasons PLS-SEM technique was chosen to analyse the data is that it allows for the evaluation of the formative measurement model, whereby the direction of all causal relationships are from the indicator to the construct (i.e., constructs are described by indicators; Hair et al., 2014). Constructs can be specified in either the reflective measurement model or the formative measurement model. In the reflective measurement model, the direction of all causal relationships is from the construct to the indicator (i.e., constructs determine indicators). All measurement models in this study are formative measurement models; common assessments of validity cannot be applied to evaluate such measurement models (Henseler et al., 2009). The systematic evaluation of PLSSEM was conducted based on the guidelines provided by Hair et al. (2014). Table 1 shows the steps involved in the evaluation of the measurement model.

The existence of collinearity among formative indicators could potentially influence the significance and weights of the indicators (Diamantopoulos et al., 2008). Tolerance index (TI) and variance inflation factor (VIF) are the two indices used to assess collinearity acceptance level. In PLS-SEM context, collinearity issue arises if the tolerance value is 0.20 or less and if the VIF value is 5.0 or higher (Hair et al., 2014). Table 2 shows the collinearity statistics of number sense, operation sense, symbol sense, pattern sense, and algebraic thinking. The tolerance values of all variables were above 0.20 , falling in the range between 0.663 and 0.886 . Similarly, the VIF values of all variables were less than 5.0, falling in the range between 1.129 and 1.508 . Therefore, collinearity was not an issue in the present study.
The next step in the evaluation process was to measure the indicator's statistical significance and the relevance of outer weights. The evaluation process involves assessing the indicator's significance by examining the $t$-values. The indicator is significant if the $t$-value is more than 1.96. Table 3 shows that the indicators of all constructs were significant based on their $t$-values except indicator Total01 (i.e., $t=1.135$ ).

However, Hair et al. (2014) suggested that the item can still be retained even if the indicator's weight is insignificant, but the corresponding item loading is relatively high (i.e., loading more than 0.50). In cases where the indicator's weight is insignificant and outer loading is less than 0.50 , the item can still be retained if the outer loading is significant (i.e., $p<0.05$ ). As such, the indicator Total01 was retained in the present study because its outer loading was significant (i.e., $t=2.161$ ). In sum, all formative models used in the present study were free from multicollinearity issues and the formative indicators were significant and relevant.

\section{Evaluation of Structural Model}

As illustrated in Table 1, the second step in the process was to evaluate the structural model which was depicted in Figure 5. Table 4 shows the bootstrapping settings used to evaluate the significance level of path coefficients while Table 5 displays the significance testing results of the structural model path coefficients.

As shown in Table 5, all cognitive factors proposed in this study (i.e., number sense, operation sense, symbol sense, and pattern sense) contributed significantly to the Year Five pupils' algebraic thinking. In other words, these cognitive factors are significantly important in developing algebraic thinking in primary-school pupils. More precisely, symbol sense appeared to be the most important contributor to algebraic thinking $(\beta=0.286, t$ value $=7.757(>1.96))$, followed by pattern sense $(\beta=$ $0.274, t$-value $=8.935(>1.96))$ and number sense $(\beta=$ $0.248, t$-value $=8.227(>1.96))$. Operation sense had the least significant impact on algebraic thinking $(\beta=0.085$, $t$-value $=2.727(>1.96))$.

Table 2. Collinearity statistics of number sense, operation sense, symbol sense, pattern sense, and algebraic thinking

\begin{tabular}{llcc}
\hline Dependent construct & Independent construct & Tolerance value & VIF \\
\hline \multirow{3}{*}{ Number sense } & Operation sense & .878 & 1.139 \\
& Symbol sense & .750 & 1.333 \\
& Pattern sense & .720 & 1.388 \\
& Algebraic thinking & .663 & 1.508 \\
Pattern sense & number sense & .816 & 1.226 \\
& Operation sense & .886 & 1.129 \\
& Symbol sense & .767 & 1.304 \\
\hline
\end{tabular}


Table 3. Formative indicators' outer weights and significance of number sense, operation sense, symbol sense, and pattern sense

\begin{tabular}{|c|c|c|c|c|}
\hline Formative constructs & Indicators & Outer weight & Std Error & $t$-value \\
\hline \multirow{5}{*}{ Number sense } & Total01 & 0.085 & 0.075 & $1.135^{*}$ \\
\hline & Total02 & 0.199 & 0.072 & 2.754 \\
\hline & Total03 & 0.383 & 0.070 & 5.445 \\
\hline & Total04 & 0.609 & 0.060 & 10.225 \\
\hline & Total05 & 0.521 & 0.065 & 7.992 \\
\hline \multirow{3}{*}{ Operation sense } & Total06 & 0.684 & 0.105 & 6.488 \\
\hline & Total07 & 0.358 & 0.132 & 2.718 \\
\hline & Total08 & 0.273 & 0.119 & 2.295 \\
\hline \multirow{5}{*}{ Symbol sense } & Total09 & 0.179 & 0.061 & 2.917 \\
\hline & Total10 & 0.239 & 0.062 & 3.850 \\
\hline & Total11 & 0.367 & 0.061 & 5.983 \\
\hline & Total12 & 0.402 & 0.063 & 6.360 \\
\hline & Total13 & 0.445 & 0.067 & 6.676 \\
\hline \multirow{6}{*}{ Pattern sense } & Total14i & 0.454 & 0.056 & 8.056 \\
\hline & Total14ii & 0.281 & 0.064 & 4.354 \\
\hline & Total14iii & 0.235 & 0.063 & 3.727 \\
\hline & Total15i & 0.289 & 0.057 & 5.032 \\
\hline & Total15ii & 0.183 & 0.064 & 2.879 \\
\hline & Total15iii & 0.171 & 0.061 & 2.824 \\
\hline \multirow{3}{*}{ Algebraic thinking } & Generalised arithmetic & 0.289 & 0.061 & 4.695 \\
\hline & Modelling & 0.616 & 0.060 & 10.339 \\
\hline & Functions & 0.283 & 0.058 & 4.876 \\
\hline
\end{tabular}

Note: ${ }^{*} p>.05$

Table 4. Bootstrapping settings in SmartPLS

\begin{tabular}{lcc}
\hline & Selected option & Reference \\
\hline Sign changes & No sign changes & \\
Cases & 720 & Hair et al. (2014) \\
Sample & 5000 & \\
\hline Note: ${ }^{*} p>.05$ & &
\end{tabular}

Table 5. Significance testing results of the structural model path coefficients

\begin{tabular}{|c|c|c|c|}
\hline & $\begin{array}{c}\text { Path } \\
\text { coefficient }\end{array}$ & $t$-value & $\begin{array}{c}\text { Significance } \\
\text { level }\end{array}$ \\
\hline $\begin{array}{l}\text { Number sense -> } \\
\text { Algebraic thinking }\end{array}$ & 0.248 & 8.227 & 0.05 \\
\hline $\begin{array}{l}\text { Operation sense -> } \\
\text { Algebraic thinking }\end{array}$ & 0.085 & 2.727 & 0.05 \\
\hline $\begin{array}{l}\text { Symbol sense -> } \\
\text { Algebraic thinking }\end{array}$ & 0.286 & 7.757 & 0.05 \\
\hline $\begin{array}{l}\text { Pattern sense -> } \\
\text { Algebraic thinking }\end{array}$ & 0.274 & 8.935 & 0.05 \\
\hline
\end{tabular}

The predictive accuracy of the structural model was assessed using the $R^{2}$ value, which is based on the squared correlation between the dependent construct and the predicted values. According to Henseler et al. (2009), $R^{2}$ values are considered strong for dependent constructs if they are more than 0.75 , moderate if 0.50 , and weak if 0.25 . However, this suggested rule of thumb is commonly adopted by studies on marketing issues and may not be applicable for studies of other fields, such as the present study on mathematics.

Figure 10 shows the $R^{2}$ value of the dependent construct (i.e., algebraic thinking), which is 0.405 and considered to be a moderate value. This means that $40.5 \%$ of the variance in algebraic thinking is explained by the four cognitive factors. In other words, number sense, operation sense, symbol sense, and pattern sense contributed $40.5 \%$ to the development of algebraic thinking in Year Five pupils.

In terms of effect size, $f^{2}$ values of $0.02,0.15$, and 0.35 represent small, medium, and large effects respectively (Cohen, 1988). Table 6 displays the results of $R^{2}$ and $f^{2}$ values of the current study. The effect sizes of all cognitive factors on algebraic thinking were small as their values were less than 0.15 .

$Q^{2}$ is used to examine the model's predictive relevance (Hair et al., 2014), which is assured if the $Q^{2}$ value is greater than zero. The results are displayed in Table 7.

The proposed cognitive factors displayed positive relationships with Year Five pupils' algebraic thinking. The results revealed these cognitive factors to contribute $40.5 \%$ in the development of Year Five pupils' algebraic thinking. Symbol sense was found to be the most influential contributor followed by pattern sense, number sense, and operation sense. This is not surprising as the major component of algebra involves symbols. This finding is also in line with the findings of Brizuela and Schliemann (2004) who reported that tenyear-old pupils could work with problems that involved unknown amounts and are able to represent these unknowns in the equation. Children are capable of working with symbols at an early age and this notion is 


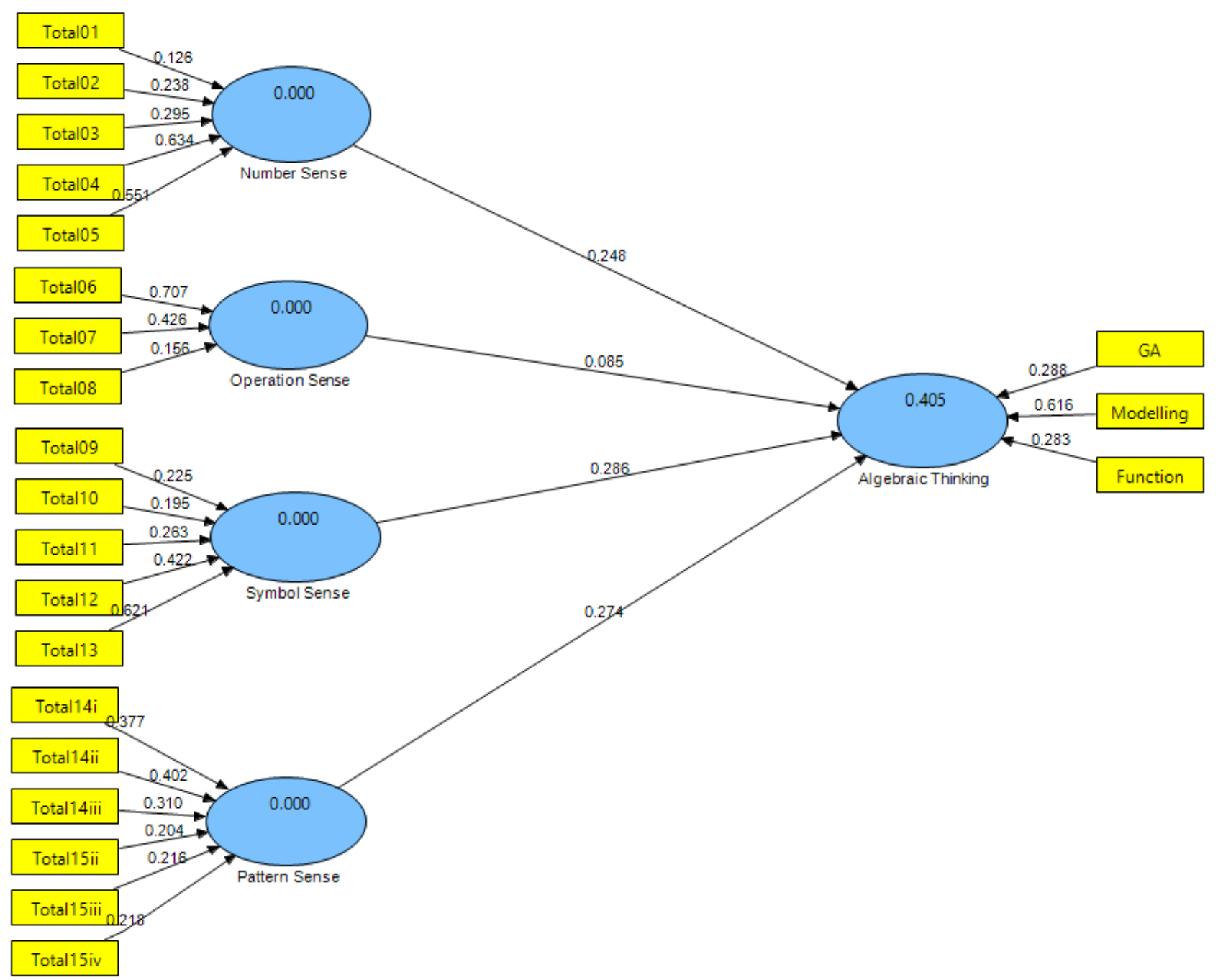

Figure 10. The conceptual model with path coefficients and $\mathrm{R}^{2}$ value of algebraic thinking

Table 6. Results of $R^{2}$ and $f^{2}$ values

\begin{tabular}{|c|c|c|c|c|}
\hline Dependent construct & Independent construct & $R^{2}$ included & $R^{2}$ excluded & $f^{2}$ \\
\hline \multirow{4}{*}{ Algebraic thinking } & Number sense & \multirow{4}{*}{0.405} & 0.354 & 0.086 \\
\hline & Operation sense & & 0.399 & 0.001 \\
\hline & Symbol sense & & 0.339 & 0.111 \\
\hline & Pattern sense & & 0.348 & 0.096 \\
\hline
\end{tabular}

Table 7. Results of $Q^{2}$ and $q^{2}$ values

\begin{tabular}{|c|c|c|c|c|}
\hline Dependent construct & Independent construct & $Q^{2}$ included & $Q^{2}$ excluded & $q^{2}$ \\
\hline \multirow{4}{*}{ Algebraic thinking } & Number sense & \multirow{4}{*}{0.243} & 0.212 & 0.041 \\
\hline & Operation sense & & 0.249 & -0.008 \\
\hline & Symbol sense & & 0.207 & 0.048 \\
\hline & Pattern sense & & 0.197 & 0.061 \\
\hline
\end{tabular}

also supported by Whitley (2019), who found that thirdgrade pupils are able to notice patterns and solve functions such as $f(x)=2 n$ and $f(x)=2 n+1$.

Pattern sense was expected to be most influential contributor to algebraic thinking, but it was found to be the second most influential in this study. Nonetheless, this finding is consistent with past literature and supports the notion that the ability to work with patterns is strongly associated with algebraic thinking (Blanton \& Kaput, 2003, 2004; Childs, 1995; Ferrini-Mundy et al., 1997; Smith, 2008). Working with patterns could build conceptual understanding of relationships and functions. Proceeding forward and backward in pattern activities would enable children to think of doing and undoing tasks (Driscoll \& Moyer, 2001), which is the most necessary skill in algebra. 
Operation sense was found to be the least influential contributor in this study, but its importance is not to be overlooked as operations are involved in every aspect such as number sense and pattern sense (Ardiansari \& Wahyudin, 2019; Slavit, 1999). Some form of addition, subtraction, or multiplication is involved in number sense tasks or patterning tasks. Thus, operation sense could not be eliminated from the conceptual model. In sum, these four cognitive factors accounted for $40.5 \%$ of the development of algebraic thinking in Year Five pupils, and elementary school curriculum and teaching instruction methods could be reformed and restructured to incorporate these factors.

\section{CONCLUSIONS}

According to Gozde and Dilek (2017), patterns and functional relationship are partially neglected in middleschool curricula textbooks; they lack generalisation questions that require students to explore beyond finding computational answers. Designing effective arithmetic content in elementary school curriculum has become increasingly important for the Ministry of Education to overcome the problems faced by middleschool students in algebra learning.

This study investigated the cognitive factors that accounted for Year Five pupils' algebraic thinking. The conceptual model provides a more comprehensive insight into the factors needed to be considered while designing an arithmetic curriculum. The findings showed that number sense, operation sense, symbol sense, and pattern sense are significant cognitive predictors of Year Five pupils' algebraic thinking, in line with past findings that highlighted the importance of these four cognitive factors.

Educators are primarily responsible for instilling number, operation, symbol, and pattern senses in class discussions and for exposing students to the relationship among these cognitive factors. As such, educators in elementary school should be provided with training on how to develop algebraic thinking and implement strategies in everyday teaching and learning sessions.

There could be other factors associated with Year Five pupils' algebraic thinking such as location, gender, and teaching instructions-future research could expand the model further by studying these factors. The current study merely established the relationship between cognitive factors and algebraic thinking and a more in-depth study should be conducted to explore this relationship further. Future studies could also use both quantitative and qualitative approaches, such as collecting quantitative data and conducting interviews, to get a more comprehensive insight into the development of children's algebraic thinking.

\section{REFERENCES}

Alibali, M. W., Knuth, E. J., Hattikudur, S., McNeil, N. M., \& Stephens, A. C. (2007). A longitudinal examination of middle school students' understanding of the equal sign and equivalent equations. Mathematical Thinking and Learning, 9, 221-247.

https:/ / doi.org/10.1080/10986060701360902

Anderson, J. C., \& Gerbing, D. W. (1988). Structural equation modeling in practice: $A$ review and recommended two-step approach. Psychological Bulletin, 103(3), 411-423. https:/ / doi.org/10.1037/ 0033-2909.103.3.411

Anderson, J. R. (1983). The architecture of cognition. Psychology Press.

Arcavi, A. (1994). Symbol sense: Informal sense-making in formal mathematics. For the Learning of Mathematics, 14(3), 24-35.

Ardiansari, L., \& Wahyudin. (2019). Operation sense in algebra of junior high school students through an understanding of distributive law. Journal of Physics: Conference Series, 1521, 032003. https:/ / doi. org/10.1088/1742-6596/1521/3/032003

Ayhan. K., \& Nilufer. Y.K., (2017). Relational thinking: The bridge between arithmetic and algebra. International Electronic Journal of Elementary Education, 10(1), 131-145. https:/ / doi.org/10.26822 /iejee.2017131893

Blanton, M. L., \& Kaput, J. J. (2003). Developing elementary teachers': "Algebra eyes and ears". Teaching Children Mathematics, 10(2), 70-77. https:// doi.org/10.5951/TCM.10.2.0070

Blanton, M. L., \& Kaput, J. J. (2004). Elementary grades students' capacity for functional thinking. In M. J. Hoines, \& A. B. Fuglestad (Eds), Proceedings of the 28th International Conference of the International Group for the Psychology of Mathematics Education (Vol. 2, pp. 135-142). Bergen University College.

Blanton, M. L., \& Kaput, J. J. (2008). Building district capacity for teacher development in algebraic reasoning. In J. J Kaput, D. W. Carraher, \& M. L. Blanton (Eds.), Algebra in the early grades (pp. 361388). Taylor \& Francis Group. https:/ / doi.org/10.4324/9781315097435-17

Brizuela, B., \& Schliemann, A. (2004). Ten-year-old students solving linear equations. For the Learning of Mathematics, 24(2), 33-40.

Byrd, C. E., McNeil, N. M., Chesney, D. L., \& Matthews, P. G. (2015). A specific misconception of the equal sign acts as a barrier to children's learning of early algebra. Learning and Individual Differences, 38, 6167. https:/ / doi.org/10.1016/j.lindif.2015.01.001

Cai, J., \& Moyer, J. (2008). Developing algebraic thinking in earlier grades: some insights from international 
comparative studies. In National Council of Teachers of Mathematics (pp. 169-193). NCTM.

Carpenter, T. P., \& Levi, L. (2000). Developing conceptions of algebraic reasoning in the primary grades (Report no. 002). Wisconsin Center for Education Research.

Carraher, D. W., \& Schliemann, A. D. (2007). Early algebra and algebraic reasoning. In F. Lester (Ed.), Second handbook of research on mathematics teaching and learning: A project of the National Council of Teachers of Mathematics (pp. 669-705). Information Age Publishing.

Carraher, D. W., Schliemann, A. D., \& Schwartz, J. L. (2008). Early algebra is not the same as algebra early. In J. J. Kaput, D. W. Carraher, \& M. L. Blanton (Eds.), Algebra in the early grades (pp. 235-272). Taylor \& Francis Group. https:/ / doi.org/10.4324/ 9781315097435-12

Carraher, D. W., Schliemann, A. D., Brizuela, B. M., \& Earnest, D. (2006). Arithmetic and algebra in early mathematics education. Journal for Research in Mathematics Education, 37(2), 87-115.

Chan, Y. L., Maun, R., \& Krishnan, G. (2018). Mathematics Year 5. Alias, A. R., Hamdan, N.A. (Eds.). Dewan Bahasa dan Pustaka.

Childs, K. M. (1995). An investigation of the role of patterns in developing algebraic thinking (UMI No. 9615789) (Doctoral dissertation), Texas A\&M University.

Chrysostomou, M., Pitta-Pantazi, D., Tsingi, C., Cleanthous, E., \& Christou, C. (2013). Examining number sense and algebraic reasoning through cognitive styles. Educational Studies in Mathematics, 83, 205-223. https://doi.org.10.1007/s10649-0129448-0

Cohen, J. (1988). Statistical power analysis for the behavioral sciences. Lawrence Erlbaum.

Diamantopoulos, A., Riefler, P., \& Roth, K. P. (2008). Advancing formative measurement models. Journal of Business Research, 61(12), 1203-1218. https:/ / doi.org/10.1016/j.jbusres.2008.01.009

Driscoll, M., \& Moyer, J. (2001). Using students' work as a lens on algebraic thinking. Mathematics Teaching in the Middle School, 6(5), 282-286. https://doi.org/10.5951/MTMS.6.5.0282

Ferrini-Mundy, J., Lappan, G., \& Phillips, E. (1997). Experiences with patterning. Teaching Children Mathematics, 3(6), 282-288. https: / / doi.org/10.5951 /TCM.3.6.0282

Gozde. A., \& Dilek, T. (2017). An analysis of middle school mathematics textbooks from the perspective of fostering algebraic thinking through generalization. Educational Sciences: Theory $\mathcal{E}$ Practice, 17(6), 2001-2030. https:/ / doi.org/10.12738 /estp.2017.6.0506
Hair, J. F., Hult, G. T., Ringle, C. M., \& Sarstedt, M. (2014). A primer on partial least squares structural equation modeling (PLS-SEM). SAGE Publications, Inc.

Haldar, L. C. (2014). Students' understandings of arithmetic generalizations (UMI No. 3640454) (Doctoral dissertation), University of California, Berkeley.

Henseler, J., Ringle, C. M., \& Sinkovics, R. R. (2009). The use of partial least squares path modeling in international marketing. New Challenges to International Marketing Advances in International Marketing, 20, 277-319. https://doi.org/10.1108/ S1474-7979(2009)0000020014

Herscovics, N., \& Linchevski, L. (1994). A cognitive gap between arithmetic and algebra. Educational Studies in Mathematics, 27(1), 59-78. https://doi.org/ 10.1007/BF01284528

Houssart, J., \& Evens, H. (2003). Approaching algebra through sequence problems: Exploring children's strategies. Research in Mathematics Education, 5(1), 197-214

https:/ / doi.org/10.1080/14794800008520122

Hsu, C. Y., Yang, D. C., \& Li, F. M. (2001). The design of "The fifth and sixth grade number sense rating scale". Chinese Journal of Science Education, 9(4), 351374.

Jacobs, V. R., Franke, M. L., Carpenter, T. P., Levi, L., \& Battey, D. (2007). Professional development focused on children's algebraic reasoning in elementary school. Journal for Research in Mathematics Education, 38(3), 258-288. https:/ / doi.org/10.2307/30034868

Jurdak, M. E., \& El Mouhayar, R. R. (2014). Trends in the development of student level of reasoning in pattern generalization tasks across grade level. Educational Studies in Mathematics, 85, 75-92. https:/ / doi.org/10.1007/s10649-013-9494-2

Kaput, J. J. (2008). What is algebra? What is algebraic reasoning? In J. J. Kaput, D. W. Carraher, \& M. L. Blanton (Eds.), Algebra in the early grades (pp. 5-17). Taylor and Francis Group. https://doi.org/ 10.4324/9781315097435-2

Kaput, J., Carraher, D. W., \& Blanton, M. L. (Eds.), Algebra in the early grades (pp. 361-388). Taylor and Francis Group.

Kieran, C. (1996). The changing face of school algebra. In C. Alsina, J. Alvarez, B. Hodgson, C. Laborde, \& A. Pérez (Eds.), 8th International congress on mathematical education: selected lectures (pp. 271-290). S.A.E.M. Thales.

Kieran, C., Pang, J., Schifter, D., \& Ng, S. F. (2016). Early algebra: Research into its nature, its learning, its teaching. Springer International Publishing. https:/ / doi.org/10.1007/978-3-319-32258-2 
Kim, J., Kim, J., DesJardins, S. L., \& McCall, B. P. (2015). Completing Algebra II in high school: does it increase college access and success? The Journal of Higher Education, 86(4), 628-662. https://doi.org/ $10.1353 /$ jhe. 2015.0018

Knuth, E. J., Alibali, M. W., McNeil, N. M., Weinberg, A., \& Stephens, A. C. (2011). Middle school students' understanding of core algebraic concepts: Equivalence \& variable. In J. Cai, \& E. Knuth (Eds.), Early algebraization (pp. 259-276). Springer. https: / /doi.org/10.1007/978-3-642-17735-4_15

Lannin, J. K., Barker, D. D., \& Townsend, B. E. (2006). Recursive and explicit rules: How can we build student algebraic understanding? Journal of Mathematical Behavior, 25, 299-317. https:// doi.org/10.1016/j.jmathb.2006.11.004

Mason, J. (2008). Making use of children's power to produce algebraic thinking. In J. Kaput, D. Carraher, \& M. Blanton (Eds.), Algebra in the early grades (pp. 57-94). Taylor and Francis Group. https: / / doi.org/10.4324/9781315097435-4

McIntosh, A., Reys, B. J., \& Reys, R. E. (1992). A proposed framework for examining basic number sense. For the Learning of Mathematics, 12(3), 2-8.

Miller, G. A. (1956). The magical number seven, plus or minus two: Some limits on our capacity for processing information. Psychological Review, 63, 8197. https:/ / doi.org/10.1037/h0043158

Ralston, N. C. (2013). The development and validation of a diagnostic assessment of algebraic thinking skills for students in the elementary grades (UMI No. 3588844) (Doctoral dissertation), University of Washington.

Rittle-Johnson, B., Matthews, P. G., Taylor, R. S., \& McEldoon, K. L. (2011). Assessing knowledge of mathematical equivalence: A construct-modeling approach. Journal of Educational Psychology, 103(1), 85-104. https:/ / doi.org.10.1037/a0021334

Schubert, C., Gfeller, M., and Donohue, C. (2013). Using Group Explorer in teaching abstract algebra. International Journal of Mathematical Education in Science, 44(3), 37-41. https://doi.org/10.1080/ 0020739X.2012.729680

Slavit, D. (1999). The role of operation sense in transitions from arithmetic to algebraic thought. Educational Studies in Mathematics, 37(3), 251-274. https:/ / doi.org/10.1023/A:1003602322232
Smith, E. (2008). Representational thinking as a framework for introducing functions in the elementary curriculum. In J. J. Kaput, D. W. Carraher, \& M. L. Blanton (Eds.), Algebra in the early grades (pp. 133-163). Taylor and Francis Group. https:/ / doi.org/10.4324/9781315097435-6

Stacey, K. (1989). Finding and using patterns in linear generalising problems. Educational Studies in Mathematics, 20(2), 147-164. https://doi.org/ $10.1007 /$ BF00579460

Swafford, J. O., \& Langrall, C. W. (2000). Grade 6 students' preinstructional use of equations to describe and represent problem situations. Journal for Research in Mathematics Education, 31(1), 89-112. https://doi.org/10.2307/749821

Swangrojn, P. (2003). Solving algebra word problems: Solution strategies Thai students used and potential connections with teachers' instructional strategies (UMI No. 3103575) (Doctoral dissertation), Oregon State University.

Van Amerom, B. A. (2002). Reinvention of early algebra (Doctoral dissertation, Utrecht University). https:/ / dspace.library.uu.nl/handle/1874/874

Warren, E. A., Cooper, T. J., \& Lamb, J. T. (2006). Investigating functional thinking in the elementary classroom: Foundations of early algebraic reasoning. Journal of Mathematical Behavior, 25, 208223. https:/ / doi.org/10.1016/j.jmathb.2006.09.006

Whitley, J. E. (2019). The unfolding of third graders' conceptualization of a function: A collective case study (UMI No. 27549067) (Doctoral dissertation), Kansas State University.

Yang, D. C. (2003). Teaching and learning number sense-An intervention study of fifth grade students in Taiwan. International Journal of Science and Mathematics Education, 1, 115-134. https://doi.org/10.1023/ A:1026164808929

Yang, D. C., \& Jan H. J. (2019). The study of primary school teachers' performance on number sense. International Journal of Information and Education Technology, 9(5), 342-349. https://doi.org/10.18178 /ijiet.2019.9.5.1224

Yang, D. C., Hsu, C. J., \& Huang, M. C. (2004). A study of teaching and learning number sense for sixth grade students in Taiwan. International Journal of Science and Mathematics Education, 2(3), 407-430. https:/ / doi.org/10.1007/s10763-004-6486-9

\section{http://www.ejmste.com}

